\title{
Formulation, Preparation and Storage potentiality Study of Mixed Squashes from Papaya, Banana and Carrot in Bangladesh
}

\author{
M. S. Kayshar ${ }^{1}$, A. Rahman ${ }^{2,}$ M. S. Sultana ${ }^{3,}$ K. Fatema ${ }^{4}$ and M. F. Kabir ${ }^{5}$ \\ ${ }^{1 \& 4}$ Lecturer, Sylhet Agricultural University, Sylhet-3100; ${ }^{2}$ Lecturer, Bangladesh Agricultural University, \\ Mymensingh-2202; ${ }^{3}$ Department of Food Technology and Rural Industries, Bangladesh Agricultural University, \\ Mymensingh-2202 and ${ }^{5}$ Scientific Officer, Bangladesh Rice Research Institute, Gazipur.
}

\begin{abstract}
The study was conducted on formulation and preparation of mixed squashes with different combinations of papaya, banana and carrot pulp. The research work was carried out in three phases. In phase $I$, the moisture content, total soluble solid (TSS), ash, pH, acidity, vitamin C (ascorbic acid), total sugar, reducing and non-reducing sugar of ripe papaya, ripe banana, fully matured carrot and processed mixed squash from these were analyzed. The pulp prepared from papaya, banana and carrot were used for preparation of mixed squash with various combinations along with other ingredients. The combinations were $100 \%$ papaya for sample $S_{1}$ (Control); $60 \%$ carrot, $20 \%$ papaya and $20 \%$ banana for sample $S_{2} ; 40 \%$ carrot, $40 \%$ papaya and $20 \%$ banana for sample $S_{3}$ and $33.33 \%$ carrot, $33.33 \%$ papaya and $33.33 \%$ banana for sample $\mathrm{S}_{4}$. Sugar and citric acid was used for improving the sweetness and lowering the $\mathrm{pH}$ respectively. Potassium meta-bisulphate (KMS) was used as preservative. In phase II, the sensory property of squash was evaluated by a taste testing panel consisting of 10 panelists. The results showed that color, flavor, sweetness, sourness and overall acceptability of the squash $S_{3}$ containing $40 \%$ carrot pulp, $40 \%$ papaya pulp and $20 \%$ banana pulp got highest score. Other samples were moderately acceptable. In phase III, the storage potentiality of squashes was observed. After 8 weeks $S_{1}$ and $S_{3}$ sample remain unchanged but other samples $S_{2}$ and $S_{4}$ were slightly changed by sedimentation.
\end{abstract}

Keyword:Preparation, Squash, Sensory evaluation and Storage potentiality.

\section{INTRODUCTION}

Fruit squashes are becoming popular in comparison with synthetic beverages evidently because of their taste, flavor, nutritive value and their storage stability. The beverage product squash has a good demand in this subcontinent as well as many other foreign countries. A number of research worker in different countries investigated the formulations of different fruit based on soft drinks, squash, non-carbonated fruit juice drink etc. containing sugar, water, citric acid, KMS, artificial color and flavor (Ahmad, et al. 1988). A fruit juice beverage is a clear or nearly clear unfermented liquid which is developed from the removal of the sweet watery sap from live fruits. This beverage may be served as fresh juice drink as soon as it is expressed from the fruit. It could also be processed then packaged for future use as a processed juice such as squash (Gatchalian and De Leon, 1992). According to Sikder (1999) beverages are characterized by two principal characters. Firstly, they are liquid or consumed in a liquid state. Secondly, they are generally used to quench the thirst. One of the groups of beverages is still beverage such as fruit juices and fruit squashes.

Squash is a diluted fruit juice. Among all beverages squash is quite popular all over the world as nutritious soft drinks. It consists essentially of strained juice containing moderate quantities of fruit pulp to which sugar is added for sweetening. Acid is added to lower the $\mathrm{pH}$ which arrests the growth of microorganisms responsible for spoilage of the product. Acid in combination with sugar also improve the taste of sugar. Sulphur dioxide $\left(\mathrm{SO}_{2}\right)$ is used as a preservative to prevent non-enzymatic browning reaction. There are various aspects for which mixed squash made from papaya, banana and carrot may be popular for- fills up the thirst more easily, rich source of vitamins and minerals, increases the metabolism system, speeds up the digestion of carbohydrates and fats, good for people who are trying to lose weight naturally, good for improvement in the immunity system of the body, provides high nutritive and medicinal value and helps to treat anemia, circulatory problems and skin disorders.

The preparation of squashes had been investigated by a number of research workers in different parts of the world. Keeping in view of the above circumstances the present investigation was planned with the objectives to find out the suitable formulation for mixed squashes based on papaya, banana and carrot; to evaluate the proximate composition of mixed squash; to study the sensory evaluation of the final product; and to study the storage potentiality of final product. 


\section{MATERIALS AND METHODS}

The study was conducted in the laboratory of the Department of Food Technology and Rural Industries under the Faculty of Agricultural Engineering and technology, Bangladesh Agricultural University, Mymensingh. The fresh ripe papaya (88\% moisture content), fresh ripe banana ( $72 \%$ moisture content) and matured carrots (96\% moisture content) were procured from the local market and cleaned thoroughly with potable water before preparation of pulps. Chemicals and solvents used in the study were of AR grade and water was glass distilled unless specified otherwise. Sugar was procured from the local market. Potassium Metabisulphite (KMS), citric acid and other materials required were used from the laboratory stock.

At first, pulp was extracted from papaya, banana and carrot. For extraction, fresh and ripe papaya and banana was collected. In case of carrot, matured one was procured from local market. Then papaya, banana and carrot was washed thoroughly, peeled and cut into slices. Pulp was collected by cutting out the flesh of papaya. On the other hand, banana and carrot slices were steam blanched to prevent browning reaction and to make the texture soft respectively. Then the pulp was blended in an electric blender separately. After proper blending papaya, banana and carrot pulp was screened through a mosquito net. The pulp was stored in a deep freeze at a temperature of $-20^{\circ} \mathrm{C}$ for future use. The analysis was done on prepared pulp. The prepared pulp of papaya, banana and carrot were analyzed for their moisture content, ash content, total soluble solids (TSS), acidity (as citric acid), $\mathrm{pH}$ and vitamin $\mathrm{C}$ content. Moisture content, ash content, acidity as citric acid and vitamin $\mathrm{C}$ (ascorbic acid) were determined by adopting AOAC (2005) method for papaya, banana and carrot pulp. Total Soluble Solids (TSS) was measured by the refractometer (Model No.: 8987 Puji Kuki Ltd. Tokio). The pulp of papaya, banana and carrot were placed on the prism glass of refractometer and readings were recorded through eye piece for TSS measurement respectively. The $\mathrm{pH}$ of the pulp was measured by using PERKINFLEMER Metrin $\mathrm{V} \mathrm{pH}$ at an ambient temperature. Reducing sugar, non reducing sugar, and total sugar was estimated according to the methods of Rangana, (1979).

After that, according to specification, squash was formulated. The required specification was TSS: 40\%; Acidity: $1.25 \%$; Juice pulp: $25 \%$; KMS: $350 \mathrm{ppm}\left(\mathrm{SO}_{2}\right)$. The formulations of squashes were coded as $\mathrm{S}_{1}, \mathrm{~S}_{2}, \mathrm{~S}_{3}$ and $\mathrm{S}_{4}$ for the study.

$\mathrm{S}_{1}=$ papaya $(100 \%) \rightarrow$ Control; $\mathrm{S}_{2}=\operatorname{carrot}(60 \%):$ papaya $(20 \%):$ banana $(20 \%)$;

$\mathrm{S}_{3}=\operatorname{carrot}(40 \%):$ papaya $(40 \%):$ banana $(20 \%) ; \mathrm{S}_{4}=\operatorname{carrot}(33.33 \%):$ papaya $(33.33 \%):$ banana $(33.33 \%)$

For $500 \mathrm{ml}$ of each sample: KMS required $=\frac{(350 \times 222 \times 500)}{\left(10^{6} \times 128\right)}$

Acid to be added $=($ acid required - acid present in pulp $)$

Sugar to be added $=$ TSS required $-($ TSS present + acid to be added + KMS required $)$

Water to be added $=500-($ pulp + acid to be added + KMS required + Sugar to be added $)$

The formulations of all samples are given in Table 1 .

Table 1: Formulations of the squashes

\begin{tabular}{|l|c|c|c|c|}
\hline \multirow{2}{*}{ Ingredients (based on \% finished product) } & \multicolumn{4}{|c|}{ Samples } \\
\cline { 2 - 5 } & $S_{I}$ (Control) & $S_{2}$ & $S_{3}$ & $S_{4}$ \\
\hline Pulp (gm) & 125 & 125 & 125 & 125 \\
\hline Sugar (gm) & 181.3 & 186.43 & 187.68 & 181.3 \\
\hline KMS (gm) & 0.303 & 0.303 & 0.303 & 0.303 \\
\hline Citric acid (gm) & 5.76 & 5.76 & 5.76 & 5.76 \\
\hline Water (ml) & 162.5 & 182.5 & 181.34 & 162.5 \\
\hline
\end{tabular}

For preparing squash given method was followed. At first, Pulp, sugar, citric acid and KMS were separately weighed and water also measured according to the calculation. Then small quantity of water was taken out from the measured quantity of water to dissolve KMS later on. Sugar and citric acid were mixed with water and heated to prepare syrup and the syrup was filtered through a coarse cloth and then cooled. After that, KMS was dissolved in aforesaid quantity of water that was measured earlier. Measured pulp was then mixed with the cool syrup. Then KMS dissolved in water was also added and mixed thoroughly and squash was prepared. Finally, squash was poured in sterilized bottle and sealed carefully. Again analysis was done on prepared squash. Prepared squashes were analyzed for its total soluble solids, $\mathrm{pH}$, acidity, vitamin $\mathrm{C}$, reducing sugar, non reducing sugar and total sugar according to the reference methods outlined before.

Sensory evaluation was performed to judge the acceptability of different formulated products by panelists. The taste testing panel was consisting of 10 taste panelists. They were asked to evaluate color, flavor, 
sweetness, sourness by a scoring rate on a 9 point hedonic scale. $9=$ like extremely, $8=$ like very much, $7=$ like moderately, 6 = like slightly, $5=$ neither like or nor dislike, $4=$ dislike slightly, $3=$ dislike moderately, $2=$ dislike very much , $1=$ dislike extremely. The data were analyzed for ANOVA in Completely Randomized Design (CRD) under computerized statistical method of M-stat and Duncan's New Multiple Range Test (DMRT) was used to compare the mean. Finally, the effect of storage ( 8 weeks) time on the properties of mixed squash prepared from papaya, banana and carrot was studied.

\section{RESULTS AND DISCUSSION}

The initial composition of papaya, banana and carrot pulp were analyzed for their moisture content, TSS, reducing sugar, non reducing sugar, ash, $\mathrm{pH}$, acidity and ascorbic acid. The results are shown in table 2 .

Table 2: Composition of pulp used for preparation of mixed squash

\begin{tabular}{|c|c|c|c|c|c|c|c|c|c|}
\hline Products & Moisture\% & TSS\% & $\begin{array}{l}\text { Total } \\
\text { sugar\% }\end{array}$ & $\begin{array}{l}\text { Reducing } \\
\text { Sugar\% }\end{array}$ & $\begin{array}{l}\text { Non reducing } \\
\text { sugar\% }\end{array}$ & Ash & pH & Acidity\% & $\begin{array}{l}\text { Vitamin C } \\
\mathrm{mg} / 100 \mathrm{~g}\end{array}$ \\
\hline Papaya & 88 & 10 & 5.90 & 4.10 & 1.80 & 0.01 & 5.7 & 0.39 & 61.8 \\
\hline Banana & 72 & 10 & 18.25 & 11.50 & 6.75 & 0.01 & 5.7 & 0.37 & 26.56 \\
\hline Carrot & 94 & 8 & 28.50 & 18.75 & 6.75 & 0.01 & 5.8 & 0.40 & 19.70 \\
\hline
\end{tabular}

Source: Author's Estimation (2013)

Four different types of squashes were prepared with different combinations of papaya, banana and carrot pulp. These formulations were shown in table 1. Squashes were bottled and stored at room temperature for 56 days in the laboratory. TSS, Vitamin $\mathrm{C}$, acidity, $\mathrm{pH}$, reducing sugar, non- reducing sugar and total sugar present in squashes have been estimated during this storage period and shown in Table 3.

Table 3: Effect of Storage Time on the Properties of Mixed Squash Prepared from Papaya, Banana and Carrot

\begin{tabular}{|c|c|c|c|c|c|c|c|c|}
\hline $\begin{array}{l}\text { Storage } \\
\text { Period }\end{array}$ & Sample & TSS $\%$ & $\mathrm{pH}$ & Acidity $\%$ & $\begin{array}{c}\text { Reducing } \\
\text { sugar\% }\end{array}$ & $\begin{array}{l}\text { Non-reducing } \\
\text { sugar } \%\end{array}$ & $\begin{array}{l}\text { Total } \\
\text { sugar\% }\end{array}$ & $\begin{array}{c}\text { Vitamin C }(\mathrm{mg} / 100 \\
\mathrm{gm})\end{array}$ \\
\hline \multirow[t]{4}{*}{ Initial } & $S_{1}$ & 39.00 & 5.21 & 1.24 & 20.70 & 17.10 & 36.75 & 2.24 \\
\hline & $S_{2}$ & 40.00 & 5.15 & 1.24 & 21.85 & 16.88 & 37.65 & 2.15 \\
\hline & $S_{3}$ & 40.00 & 5.09 & 1.25 & 20.65 & 16.10 & 37.80 & 2.11 \\
\hline & $S_{4}$ & 40.00 & 5.03 & 1.25 & 20.15 & 15.90 & 38.85 & 2.10 \\
\hline \multirow[t]{4}{*}{2 weeks } & $S_{1}$ & 39.00 & 5.25 & 1.23 & 20.89 & 17.09 & 37.98 & 2.15 \\
\hline & $S_{2}$ & 40.00 & 5.16 & 1.24 & 22.10 & 16.80 & 38.90 & 2.09 \\
\hline & $S_{3}$ & 40.00 & 5.12 & 1.25 & 20.20 & 16.00 & 36.20 & 2.06 \\
\hline & $S_{4}$ & 40.00 & 5.05 & 1.25 & 20.30 & 15.85 & 36.15 & 2.05 \\
\hline \multirow[t]{4}{*}{4 weeks } & $S_{1}$ & 39.30 & 5.31 & 1.21 & 21.38 & 17.01 & 38.39 & 2.01 \\
\hline & $S_{2}$ & 40.00 & 5.17 & 1.22 & 22.42 & 16.70 & 36.17 & 2.03 \\
\hline & $S_{3}$ & 40.40 & 5.15 & 1.24 & 20.48 & 15.80 & 39.12 & 1.98 \\
\hline & $S_{4}$ & 40.50 & 5.08 & 1.24 & 20.67 & 15.50 & 36.28 & 1.95 \\
\hline \multirow[t]{4}{*}{6 weeks } & $S_{l}$ & 39.90 & 5.35 & 1.19 & 21.45 & 17.55 & 39.00 & 1.82 \\
\hline & $S_{2}$ & 40.10 & 5.17 & 1.21 & 22.51 & 16.77 & 39.28 & 1.91 \\
\hline & $S_{3}$ & 40.50 & 5.19 & 1.23 & 20.55 & 15.84 & 36.39 & 1.86 \\
\hline & $S_{4}$ & 40.65 & 5.11 & 1.24 & 20.90 & 15.55 & 36.65 & 1.85 \\
\hline \multirow[t]{4}{*}{8 weeks } & $S_{I}$ & 40.40 & 5.41 & 1.15 & 21.55 & 15.95 & 39.20 & 1.62 \\
\hline & $S_{2}$ & 40.15 & 5.22 & 1.20 & 22.71 & 17.62 & 39.69 & 1.84 \\
\hline & $S_{3}$ & 40.65 & 5.25 & 1.22 & 21.25 & 17.65 & 37.20 & 1.73 \\
\hline & $S_{4}$ & 40.90 & 5.16 & 1.23 & 21.10 & 17.01 & 36.80 & 1.71 \\
\hline
\end{tabular}

Source: Author's Estimation (2013)

Total Soluble Solids (TSS) initially adjusted in formulations. $S_{1}, S_{2}, S_{3}$ and $S_{4}$ showed a negligible change through the 56 days storage periods at room temperature (Table 3). It was observed that the range of TSS increased. This range was similar to that range as reported by Rangana, (1979). The percentage change of TSS is greater in last two weeks (7th and 8th weeks) than other weeks and it is due to conversion of carbohydrate and acid into sugar.

Acidity was calculated on the basis of titrable acidity. Acidity for all the squashes at various storage periods was determined and results indicated that acidity of all formulations varied directly with the storage period and it was gradually decreased. Rangana, (1979) recommended that acidity of various fruit squashes were within the range of $1.22-1.27 \%$. This implies that the amount of papaya, banana and carrot pulp affected the acidity of the squash. The acidity of the samples $S_{3}$ and $S_{4}$ were more acidic than $S_{1}$ and $S_{2}$ (Table 3). Slight 
variations in $\mathrm{pH}$ were observed throughout 56 days storage period in all the formulations. The relationship between $\mathrm{pH}$ and acidity is interrelated. The lower the $\mathrm{pH}$, the higher the acidity occurred during the storage period at room temperature. Samples $S_{1}$ and $S_{2}$ had highest $\mathrm{pH}$ than the squash $\mathrm{S}_{3}$ and $\mathrm{S}_{4}$ (Table 3). The change in $\mathrm{pH}$ is associated with number of reasons; it might be due to the effect of heat treatment on the biochemical condition of the fruits and vegetables and slower rate of respiration and metabolic activity (Jitareerat, et al. 2007). The vitamin $\mathrm{C}$ or ascorbic acid of four squashes was determined during 56 days storage periods. It has been seen that vitamin $\mathrm{C}$ decreased with increase of storage period (Table 3). The loss of vitamin $\mathrm{C}$ is due to the oxidation of vitamin C. During processing of the squashes, few factors, like heat treatment, agitation etc. may accelerate the destruction of vitamin $\mathrm{C}$ in the formulations. Oxidation of ascorbic acids may be caused by several factors including exposure to $\mathrm{O}_{2}$, light, heat, metal, alkaline $\mathrm{pH}$ (Sritananan, et al. 2005). The initial reducing sugar content and reducing sugar content during the storage period of all squashes showed in Table 3. During the storage period reducing sugar contents of the four squashes gradually increased. Ewaidah (1992) also reported that the reducing sugar increased due to the hydrolysis of sucrose present in fruit pulp.

The non reducing sugar content of all squashes has been shown in Table 3. Every sample was slightly decreased during 56 days storage period. This is due to the conversion of some non reducing sugar to reducing sugar through the process of glucogenesis. Hamed (1996) reported that sugar, vitamin and organic acid in carrot pulp were changed during storage. He also found that the levels of non-reducing sugar decreased and reducing sugar increased in all the preservation treatment employed, such as pasteurization at $85^{\circ} \mathrm{C}$. Sugar used in the manufacturing of soft drinks should be free of mesophilic bacteria, yeasts and molds. If any sugar containing product contains bacteria, yeast and mold then non-reducing sugar decreased rapidly because of this biological agents accelerate the conversion of non-reducing to reducing sugar. The non- reducing and reducing sugar in product is determined to know the product quality.

Total sugar content of the four squashes is considered one of the basic criteria to evaluate the squash quality. It was observed that a negligible variation in the total sugar content through its 56 days storage period at room temperature (Table 3). This variation occurred might be due to technical measuring error and slightly metabolic activity. Ali (1965) studied the storage stability of ascorbic acid in fruit juices indicated that decrease in ascorbic acid content occurred during storage. He also reported that increase in reducing sugars in canned orange juice may be due to conversion of non reducing sugars to reducing sugars. The color of all processed squashes was observed during the 56 days storage period. The color of $S_{1}$ and $S_{3}$ remained unchanged but the other two $S_{2}$ and $S_{3}$ were slightly changed due to biochemical change and metabolic activity. It is also due to the slight technical measuring error.

The four squashes were judged by a taste testing panel of 10 judges. The mean scores for color, flavor, sweetness, sourness and overall acceptability of the samples were evaluated and the mean score of the responses are presented in the Table 4. A two way analysis of variance indicated that all the sensory attributes of different squash are significantly $(\mathrm{p}<0.05)$ different. The DMRT test revealed that the color of squashes $\mathrm{S}_{1}$ and $\mathrm{S}_{3}$ significantly better. Squash $S_{2}$ had shown the least color acceptability than other squashes (Table 4). The flavor of squash $S_{3}$ was most preferred than other squashes. In comparison of flavor, squash $S_{3}$ and $S_{1}$ were significantly better than $S_{2}$ and $S_{4}$ squashes. Among all sample of squashes, flavor of $S_{2}$ sample was less acceptable. Artificial flavor may be used to overcome this situation (Table 4).

Table 4: Mean Sensory Score of Mixed Squash

\begin{tabular}{|c|c|c|c|c|c|}
\hline \multirow{2}{*}{ Sample } & \multicolumn{5}{|c|}{ Sensory attributes } \\
\cline { 2 - 6 } & Color & Flavor & Sweetness & Sourness & Overall acceptability \\
\hline$S_{1}$ & $7.0^{\mathrm{b}}$ & $6.8^{\mathrm{b}}$ & $6.5^{\mathrm{b}}$ & $6.6^{\mathrm{b}}$ & $6.7^{\mathrm{b}}$ \\
\hline$S_{2}$ & $5.8^{\mathrm{c}}$ & $5.6^{\mathrm{c}}$ & $6.3^{\mathrm{c}}$ & $5.8^{\mathrm{c}}$ & $8.0^{\mathrm{a}}$ \\
\hline$S_{3}$ & $7.9^{\mathrm{a}}$ & $7.6^{\mathrm{a}}$ & $7.8^{\mathrm{a}}$ & $6.3^{\mathrm{ac}}$ & $6.4^{\mathrm{bc}}$ \\
\hline$S_{4}$ & $6.4^{\mathrm{ab}}$ & $6.4^{\mathrm{bc}}$ & $6.4^{\mathrm{bc}}$ & 0.7133 & 0.6262 \\
\hline LSD & 0.7893 & 0.5362 & 0.7781 & \\
\hline
\end{tabular}

Source: Author's Estimation (2013)

Sweetness of the squash $\mathrm{S}_{3}$ was most preferred and significantly different than other squashes. The sweetness of the squash $S_{1}$ and $S_{4}$ were significantly better than other squashes $S_{2}$. The squash $S_{2}$ had shown less sweetness acceptability among the samples. The Sourness of squash $S_{3}$ significantly better than other squashes $S_{1}, S_{2}$ and $S_{4}$. In both cases, the squash $S_{2}$ had shown less acceptability among the squashes (Table 4).

Overall acceptability of squash $S_{3}$ was most preferred and significantly different than other squashes $S_{1}$, $S_{2}$ and $S_{4}$. The sample $S_{2}$ and $S_{4}$ had shown least satiety when compared with other squashes. 


\section{SUMMARY AND CONCLUSION}

Papaya, banana and carrot were collected from local market. All raw materials were cleaned and the undesirable materials were removed before use. Pulp were prepared from papaya, banana and carrot and stored at $-20^{\circ} \mathrm{C}$ for future use. The initial composition of papaya, banana and carrot pulp were analyzed for their moisture content, TSS, total sugar, reducing sugar, non reducing sugar, ash, $\mathrm{pH}$, acidity and ascorbic acid. The pulp prepared from papaya, banana and carrot were used for preparation of mixed squash with various combinations of the prepared pulps and other ingredients. The combinations are $100 \%$ papaya for squash $\mathrm{S}_{1}$ (Control); $60 \%$ carrot, $20 \%$ papaya and $20 \%$ banana for squash $\mathrm{S}_{2} ; 40 \%$ carrot, $40 \%$ papaya and $20 \%$ banana for squash $\mathrm{S}_{3}$ and $33.33 \%$ carrot, $33.33 \%$ papaya and $33.33 \%$ banana for squash $\mathrm{S}_{4}$. Above four types of squash $\mathrm{S}_{1}$, $\mathrm{S}_{2}, \mathrm{~S}_{3}$ and $\mathrm{S}_{4}$ were analyzed for their TSS, total sugar, reducing sugar, non reducing sugar, $\mathrm{pH}$, acidity and ascorbic acid. The effect of storage time on the mixed squash was observed an interval of $0,14,28,42$ and 56 days. Two way analysis of variance by ranks was used for sensory quality judgment. The Least Significant Difference (LSD) test was used for the comparison of means whenever the test yielded a significant result. Negligible change was observed (except the vitamin C) in the composition of the prepared squashes throughout the entire storage period. Remarkable decrease of vitamin $\mathrm{C}$ was found in the formulation during storage period and TSS, pH, and non-reducing sugar increased slightly and reduced sugar decreased slightly. Statistical analysis of the score response by the taste testing panelist on the sensory attributes of squashes revealed that color, flavor, sweetness, sourness and overall acceptability of the differently treated squashes were significantly $(\mathrm{p}<0.05)$ different. It was found that color, flavor, sweetness and overall acceptability of the squash $\mathrm{S}_{3}$, containing $40 \%$ papaya, $40 \%$ banana and $20 \%$ carrot pulp was more acceptable than that of the other formulated squash $\mathrm{S}_{1}, \mathrm{~S}_{2}$ and $\mathrm{S}_{4}$.

Now-a-days, juices or squashes available in market are equally popular to all age group of people. Due to high moisture content and sugar content it is readily susceptible to spoilage and quality deterioration. In developed countries, the quality of fruit processed products like juices or squashes is strictly maintained through laws, regulations and proper monitoring system; but in many developing and less developed countries, the manufacturer is not concerned about the nutritional quality, chemical safety, microbiological safety and hygiene of fruit juices because of lack of enforcement of the law and monitoring system. Thus the transmission of some human diseases through juice and other drinks are considered a serious problem in recent years. So, special care should be taken during processing to avoid microbial contamination and quality deterioration. Types of sugars used (other than sucrose) should be declared on the label. If preservatives are added their name and specific quantity should be declared on the label. Enforcing law and imposing punishment, social motivation of food processor, social motivation of food consumers and strengthening supervision by legal authority to control adulteration and improve the product quality. More research works would be needed to find out suitable formulation for squashes, minimize the loss of vitamin $\mathrm{C}$ during storage content and to improve the quality of the mixed squashes

\section{References}

[1] Ahmad, M. Chaudhury, M.A. Khan. (1988). Technological studies on citrus and other fruit based drinks. Nucleus 23(3/4): 41-45

[2] Ali, M. (1965), Canning of fruits vegetables and their juices, Effect of canning and storage on the quality of juice from different varieties of oranges, M.Sc.thesis, Department of Food Technology, Agricultural University Faisalabad.

[3] Ewaidah, E. H. (1992). Studies on commercially canned juices produced locally in Saudi Arabia. Physicochemical organoleptic and microbiological assessment. Food Chemistry 44(2): 103-111.

[4] Gatchalian, M.M. and S.Y. De Leon. (1992). Introduction to Food Technology. Manila, Philippines. Merriam and Webster Bookstore, Inc.: 130-131.

[5] Hamed. (1996). Storage stability of carrot pulp at various condition and treatment. Indian Food Packer 45(3): 48-53.

[6] Jitareerat, P. S. Paumchai and S. Kanlayanarat. (2007). Effect of chitosan on ipening enzymatic activity, and disease development in papaya (Carica papaya) fruit. New Zealand J. Crop Hort. Sci., 35: 211-218.

[7] Rangana, S. (1979). Manual of analysis of fruit and vegetables products. Tata McGrow-Hill publishingcompany limited. New Delhi. 94-101.

[8] Sikder, S.S. (1999). Production of ready to eat drink mango juice and studies of storage life. 